\title{
Myopic decision making in energy system decarbonisation pathways. A UK case study.
}

Francesco Fuso Nerini ${ }^{1,2}$, Ilkka Keppo ${ }^{1}$, Neil Strachan ${ }^{1}$

${ }^{1}$ UCL Energy Institute, University College London, London, UK

${ }^{2}$ Unit of Energy Systems Analysis, Royal Institute of Technology (KTH-dESA), Stockholm, Sweden

*Corresponding author: f.fusonerini@ucl.ac.uk. UCL Energy Institute, University College London, 14 Upper Woburn Place, London WC1H 0NN

\begin{abstract}
With an application on the UK, this paper shows that myopic planning might result in delayed strategic investments and in considerably higher costs for achieving decarbonisation targets compared to estimates done with perfect foresight optimisation energy models. It also suggests that carbon prices obtained from perfect foresight energy models might be under-estimated. The study was performed using a combination of the standard UK Times Model (UKTM), a perfect foresight, bottom-up, technology-rich cost optimisation energy model, and its myopic foresight version: MyUKTM. This also demonstrates that using perfect foresight optimisation models in tandem with their myopic equivalents can provide valuable indications for policy design.
\end{abstract}




\section{Introduction}

The UK legislated an ambitious target to tackle climate change: an $80 \%$ of reduction in greenhouse gases (GHG) emissions by 2050, compared to the 1990 levels [1]. For that to happen a number of 'carbon budgets' are being legislated [2]. Those set 5-year 'budgets' for all GHG emissions in the UK. The budgets are suggested by the Committee on Climate Change (CCC) to achieve the 2050 target with a 'cost-effective pathway'. The carbon budget proposed by the CCC are then approved and legislated by the UK's Department for Business, Energy \& Industrial Strategy (BEIS) ${ }^{1}$. Five carbon budgets have been legislated to date (Figure 1). To achieve the carbon budgets GHG emissions can be curbed in the so called 'traded' and in the 'non traded' sectors. The first one refers to sectors of the economy covered by the EU Emission Trading system (EU ETS), primarily electricity generation and energy-intensive industry. The second covers all emissions outside EU ETS, including transport, heating in buildings, agriculture, waste and some of the industry.

\section{Figure 1 UK's approved and under review carbon budgets [2]}
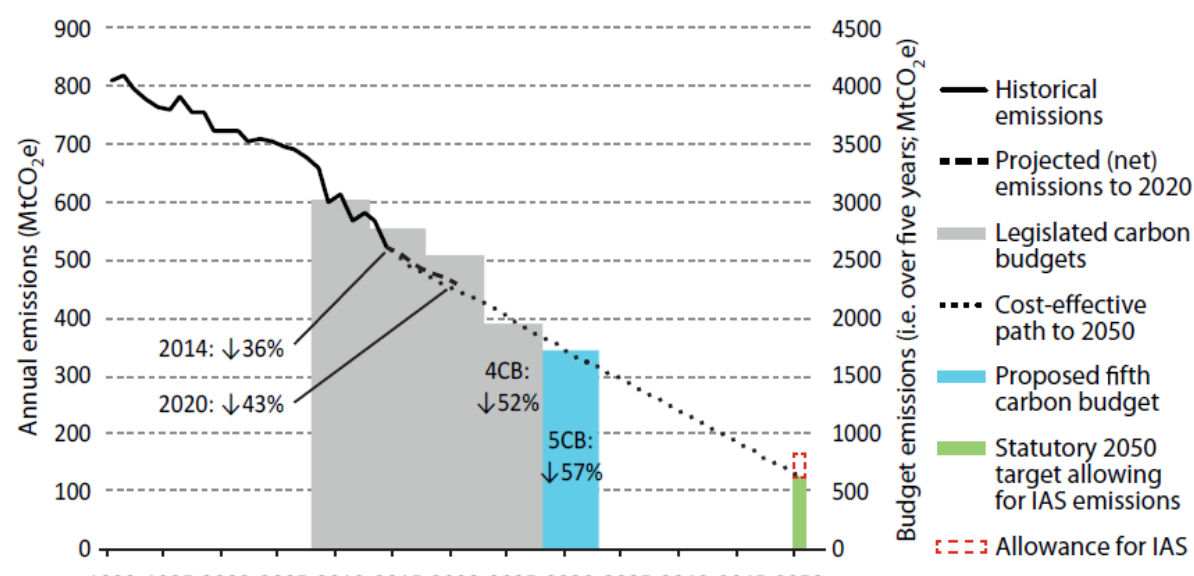

1990199520002005201020152020202520302035204020452050

In this context, both BEIS and the CCC use perfect foresight optimisation energy models, among other tools, to translate these reduction goals into roadmaps and actionable strategies. For instance, to develop some of the past Carbon Plan strategies to 2050, BEIS used the UK MARKAL [3] and ESME cost-optimisation models [4]. UK MARKAL was also used for the Energy White Paper [5]. The UK TIMES (UKTM) model [6], a cost-optimisation energy model substituting MARKAL, is intensively used in policy making. Recently, UKTM was used by BEIS for the impact assessment of the $5^{\text {th }}$ carbon budget proposed by the CCC [7].

Also internationally, cost-optimisation energy models have been extensively used to support national and regional energy planning. For instance, several TIMES (The Integrated MARKAL-EFOM System) - based optimisation models are being used by international organisations and governmental

\footnotetext{
${ }^{1}$ Formerly Department of Energy and Climate Change (DECC)
} 
institutions for providing insights on how to reach national and international climate goals [8]. Similarly, IIASA's MESSAGE model is used to provide inputs for major international assessments and scenario studies, such as the Intergovernmental Panel on Climate Change (IPCC) and the Global Energy Assessment (GEA) [9]. Open source optimisation models, such as OSeMOSYS [10], are used to support planning in developing countries, for instance for electrification [11]. Numerous other optimisation models are being used and developed around the world to support international and national energy strategies.

In fact, energy systems optimisation models provide valuable information regarding the pathway to reach the carbon reduction goals. Given a set of modelled assumptions, optimisation energy models can provide least-cost pathways for achieving the countries decarbonisation goals. That includes indications regarding the combination of energy technologies and their build rates needed to reach the set mitigation strategies. Also, those models can provide suggestions regarding the levels at which to set the carbon price for achieving the required decarbonisation targets.

Energy systems optimisation models generally assume perfect foresight for the modelled timeframe. That assumption is valuable for informing the formulation of energy policy goals with a long term view, but turns problematic when looking at an implementation phase. In fact, long-term perfect foresight energy models clash with the short-term nature of decision making. Governmental decisions are made with a limited decision horizon and imperfect knowledge of the long term developments of those decisions [12]. There is therefore a mismatch between the models used to inform national energy strategies and the actual decisions that are taken in the energy sector. Changing circumstances (e.g. governments, policies and international dynamics), future uncertainties and the high-capital requirements of energy projects often result in the adoption of short-term measures and in the postponement of long-term strategic decisions. Postponing the decisions, in turn, may result in the under-achievement of the decarbonisation targets due to the time requirements needed for the transformation of the energy system [13]. On the other hand, large-scale energy projects in the nearterm can result in technology lock-ins for the future energy system (e.g. [14]).

To address these issues, optimisation models with a myopic foresight could be used in tandem with the respective perfect foresight model to better balance the short and medium term focus of decision making with the long term goals. In myopic optimisation models the foresight of the model is reduced to a limited number of years (also called as 'myopic window') that is shorter than the full timeframe studied. Therefore, decisions are re-iterated during the modelling period. This paper looks at myopic models obtained directly from technology-rich perfect foresight models. Myopic optimisation models obtained from perfect foresight models present a number of advantages. Such models can help linking normative (should happen) long term pathways with perfect foresight, to an implementation phase where planners are trying to understand what will happen as decisions are not 
intertemporally optimal. This can help policy-makers in moving from a target-setting perspective to an implementation phase in long term energy pathways. Additionally, myopic models obtained from technology rich perfect foresight models, having the same structure of the perfect foresight model, can be created with relatively little effort. For instance, TIMES-based models are by default clairvoyant (they optimise over the entire modelling horizon), though partial look-ahead (or myopic foresight) may also be employed ${ }^{2}[15]$. As a result, those myopic models have the same level of technoeconomic detail of an energy systems optimisation model. Also, the myopic version of a model has considerably lower solution times than its perfect foresight version, possibly opening its expansion for analyses with higher spatial and temporal resolution with manageable computational times [16].

In literature, limited examples of usage of myopic and perfect foresight models in tandem are present. [12] developed a myopic version of the global MESSAGE model. Results from that study show how myopic foresight results in delayed investment decisions, stronger reliance on conventional energy sources and increasing difficulty in meeting energy demand cost-effectively. The paper argues that these results may better represent real world decision making than the results given by a model that optimises for a full century with perfect foresight. A version of that myopic model was also used in [17] to evaluate the influence of mid-century decarbonisation goals on the climate change outcomes in 2100. Additionally, [18] modified the Global Energy Transition perfect foresight optimisation model for working myopically. [19] used that model in successive efforts to investigate the importance of induced technological change. The Brookhaven Energy System Optimisation Model has both a perfect foresight and a time-stepped version [20]. Additionally, numerous other myopic energy system models not obtained from technology-rich perfect foresight optimisation models exist in literature, such as SAGE [21], IKARUS [22] and BLUE [23]. Those models, however, have different applications compared to the models discussed in this paper: technology-rich optimisation models that can be used both in perfect foresight and myopic mode.

In fact, little literature is available regarding how myopic models obtained from long-term perfect foresight optimisation models could be used to provide policy-relevant insights, and no such applications exist for the $\mathrm{UK}^{3}$.

To address that gap, this paper presents an application on the UK regarding how myopic and perfect foresight models can be used jointly to support energy planning. The Myopic UK TIMES model (MyUKTM) is presented and, through scenario analysis, used in combination with the perfect foresight UKTM to give policy-relevant insights for the achievement of UK's climate goals. Generalisable results show (a) the different investment decisions that myopia can cause, (b) the increase in costs of

\footnotetext{
${ }^{2}$ This needs, however, some caution and reformulation of certain model constraints for the myopic model. For instance, cumulative cross-temporal constraints may cause problems when using the Myopic version of Times.

${ }^{3}$ It is out of the scope of this paper to include a systematic review of all energy models used in the UK. However, such a systematic review can be found at [36].
} 
reaching decarbonisation goals due to myopia in the investment decisions, and (c) the effectiveness of carbon prices obtained from perfect foresight models in myopic investment environments.

\section{Methodology}

My-UKTM was developed starting from the UK TIMES energy systems model (UKTM) [6]. UKTM is a least cost optimisation model based on life-cycle costs (2010-2050) of competing technology pathways. It is a partial equilibrium model assuming rational decision making, perfect information, competitive markets and perfect foresight. It represents the entire UK energy system and it is divided into three supply side (resources \& trade, processing \& infrastructure and electricity generation) and five demand sectors (residential, services, industry, transport and agriculture). It has a time resolution of 16 time-slices. In the model a large number of supply and demand technologies are represented to characterise the whole UK energy system. A detailed explanation of the UKTM can be found at [24].

UKTM has been used for several energy systems analyses at the UK's Department for Business, Energy \& Industrial Strategy and the Committee on Climate Change. Additionally, UKTM has been used for several research outputs. For instance, [25] used it to evaluate the impact of non-domestic upstream GHG emissions on the total UK system GHG emissions, [26] looked at the role of the UK industrial sector in reaching the UK's carbon, energy efficiency and renewable energy targets and [27] assessed how technology uncertainty may affect future low-carbon pathways. Also, [28] used UKTM to analyse pathways that achieve 'net-zero' emissions for the UK.

My-UKTM has the same input assumptions and data as the perfect foresight UKTM model, but it has myopic foresight. The limited foresight optimisation problem is implemented in the TIMES model with the TIMESTEP function [29]. With this formulation, the total model horizon is solved in successive steps. While the TIMESTEP function is endogenous in the TIMES model, some constraints in the UKTM model had to be adjusted to work in My-UKTM ${ }^{4}$. In Figure 2 the foresight options modelled in this paper are represented. In the perfect foresight model only one decision of investments, production, etc. is taken for the entire period 2010-2050. In the myopic foresight version at each step the decision is taken for the next $n$ years, and after $m$ years, another decision for $n$ years is again taken. This mirrors a decision environment where decisions are planned for the next $n$ years, and then re-evaluated after $m$ years. The decisions taken for the first $m$ years in the previous run are irreversible and fixed in the next model run $m$ years further into the future. To investigate the

\footnotetext{
${ }^{4}$ The changed constraints are cumulative inter-temporal constraints, such as cumulative emissions and capacity limits spanning over several myopic windows. In myopic Times those constraints were already reached after the first few myopic time windows creating problems in the results. For instance, a carbon budget expressed over the whole modelling timeframe (2010-2050) would be used in the first few years (e.g. 2010-2025) in the myopic model, causing infeasibilities for the successive myopic windows. To solve that, those constrains were either reformulated as linear constraints, or divided into the different myopic windows. All the reformulated constraints were implemented both in the perfect foresight and myopic UKTM to ensure the comparability of the results.
} 
dynamics of myopic investments, for this study $n$ is arbitrarily set to either 20 or 10 years, and $m$ to 10 or 5 years. Arguably, this foresight is closer to real world decision making - and real world decision making environment, in which future is uncertain (contrary to the perfect foresight assumption). For instance, rather than making decisions for the next 40 years, energy companies and utilities may take investment decisions for the next 10 or 20 years, and re-evaluate those with changing circumstances (such as changing policies - or energy prices) 5 or 10 years later.

Figure 2 foresight options studied in this paper

Perfect

foresight

\section{0y foresight,} 10y overlap

\section{0y foresight, 5 y overlap}

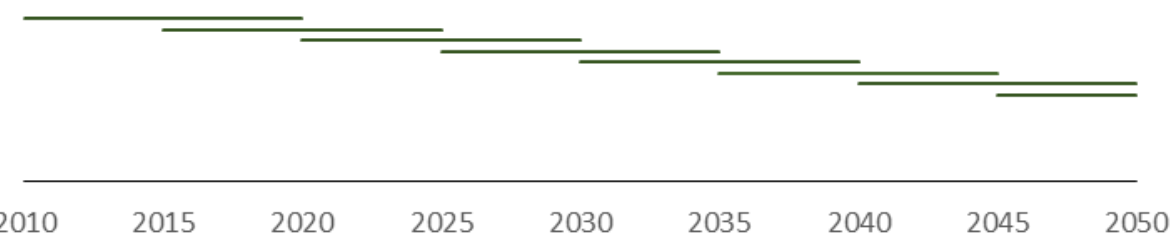

A number of scenarios are studied in this paper, and compared with a focus on the achievement of UK's decarbonisation goals. The rationale behind these scenarios is to test how different planning foresights influence the achievement of the UK's decarbonisation goals. In detail, these scenarios help investigating the differences in achieving the 2050 decarbonisation targets with either a long-term planning (perfect foresight) or an incremental (myopic) approach. This approach also mimics the policy making process in which long term targets are set early, but the means of getting there (i.e. the carbon budgets) are incremental in nature and decided gradually. In this context the scenario with perfect foresight over the planning period is compared with scenarios with different levels of myopia. The considered scenarios are:

- PF: This is the reference run in the perfect foresight UKTM model for achieving the target of $80 \%$ reduction of GHG by 2050 . The emission trajectory for achieving the decarbonisation goals is the one indicated by the UK's Committee on Climate Change [2] and reported in Figure 1. This, as indicated by the CCC, includes the five legislated carbon budgets followed by a linear decrease in emission to reach the UK's carbon targets by 2050 .

- MY-20: as PF but with a foresight of 20 years (four five-year carbon budgets) with a 10 years overlap among steps 
- MY-10: as PF but with a foresight of 10 years (two five-year carbon budgets) with a 5 years overlap among steps

- MY-20-CT: In this scenario no carbon budgets are included, but a carbon tax is obtained from the PF scenario (from the shadow price of the emission constraint) and it is applied to the MyUKTM run with a foresight of 20 years with a 10 years overlap among steps. In a perfect foresight scenario this tax trajectory would lead to the same energy system outcome as the carbon constraint used in PF

- MY-10-CT: As MY-20-CT but with a foresight of 10 years with a 5 years overlap among steps

Comparing the PF scenario with the MY-20 and MY10 scenarios can give insights regarding how plans based on long-term perfect foresight models could differ in a myopic investment environment. For instance, it might give indications on how the long-term decarbonisation targets might be achieved by agents that act myopically. This in turn, can give indication to policy-makers on which investments strategies may require stronger, additional policies in order materialise, to achieve longterm targets at the minimum societal cost.

Also, using the carbon prices suggested by the PF scenario in the MY-20-CT and MY-10-CT scenarios, this paper looks at the research question of how carbon prices obtained from a perfect foresight model perform in a myopic investment environment. Among other dynamics, it is investigated if the decarbonisation targets can be met applying those carbon prices to an energy system in which investments are made myopically. That in turn can give indications on the need of increasing carbon prices beyond what perfect foresight tools might suggest, and on the marginal costs of achieving the 'last mile' decarbonisation.

Finally, a sensitivity analysis was performed to investigate the effect flexibility of adoption of new low-carbon technologies has on the achievement of the UK decarbonisation targets both in the perfect foresight and in the myopic runs. To do that, assumptions for the diffusion constraints of low-carbon technologies were varied in the model. 


\section{Results}

\subsection{The perfect foresight least-cost decarbonisation path $\left(\mathbf{P F}^{5}\right.$ Scenario)}

The perfect foresight scenario achieves the decarbonisation goals with the least possible costs given the modelled set of assumptions. It invests from the first model year on an array of key strategic technologies both on the demand and supply side (such as low-carbon transportation and Carbon Capture and Storage (CCS)). As a result, those technologies are progressively adopted in the model, to become widely available in the last model years.

Figure 3 Final energy consumption by Sector in the UK [PJ], PF Scenario

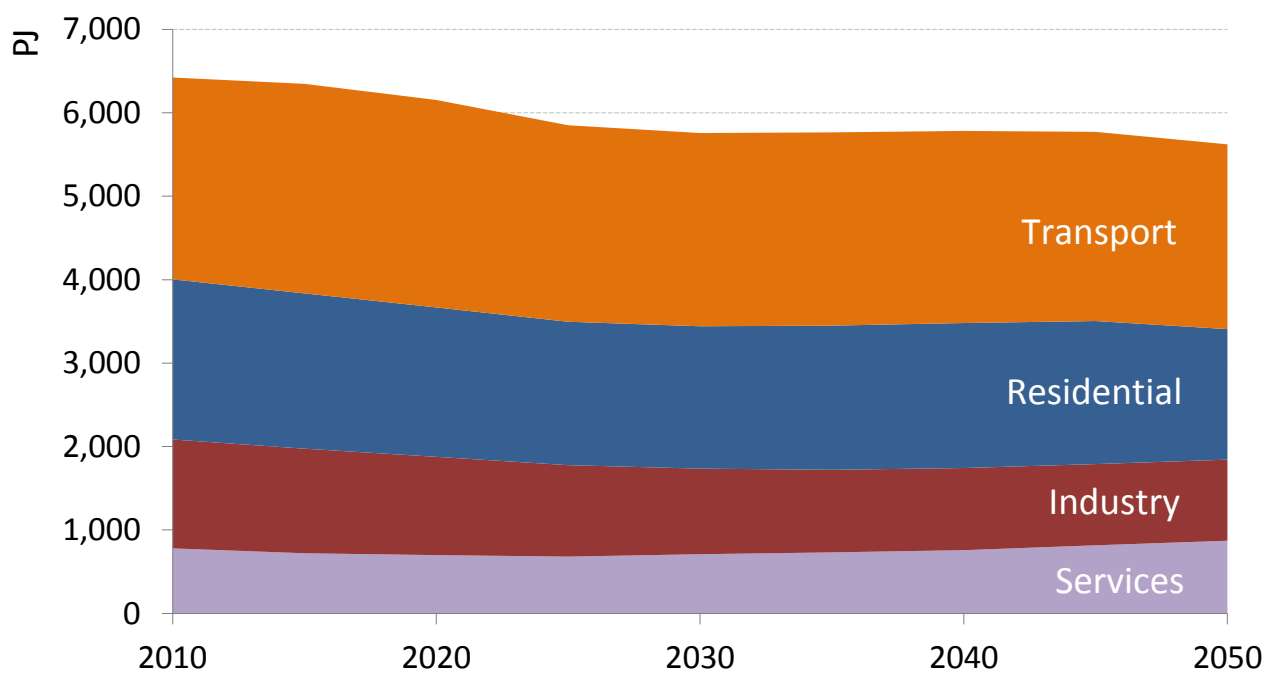

In the PF scenario, over the modelling period, total final energy consumption decreases by over $10 \%$ (Figure 3), even if the demand for energy services increases in all sectors. This is mainly due to the adoption of more efficient technologies and increased electrification for end uses. Overall, the usage of all fossil fuels decreases, while the use of electricity and renewables increases considerably.

In the residential sector, even if the final energy demand decreases by almost $20 \%$, electricity use rises by almost $30 \%$, to $570 \mathrm{PJ}$ in 2050 . Heat pumps and combined heat and power technologies play a key role in decreasing emissions of the residential sector, progressively substituting natural gas and oil based boilers by 2050. In the transport sector, while the final energy demand decreases by almost $10 \%$, both electricity- and hydrogen-based transportation rise considerably. By 2050 a quarter of the

\footnotetext{
${ }^{5}$ It is not the focus of this paper to discuss the least-cost pathway to achieve UK's decarbonisation goals, but to investigate the effects of myopia in achieving UK's decarbonisation targets and to show the value of using in tandem perfect foresight and myopic optimisation models. We therefore keep our discussion of the perfect foresight results short. Also, the PF scenario presents one possible pathway for the decarbonisation of the UK energy system, given the set of modelled assumptions. Scenarios with different input assumptions, such as technology costs, would give a different least-cost pathway (see e.g.[27]). It is however out of the scope of this paper a full scenario analysis in UKTM on how to achieve the UK decarbonisation goals.
} 
final energy demand in the transport sector is due to hydrogen and electricity usage. Similarly, in industry, the usage of more efficient technologies reduces the final energy demand by over $20 \%$, with coal (-37\%), Natural Gas (-57\%) and oil products (-88\%) being used significantly less in 2050 compared to 2015. Hydrogen plays a key role in the decarbonisation of the industrial and services sectors, where it increases to almost 500 PJ of final use in 2050. CCS also plays a role in achieving the decarbonisation goals from 2030 capturing, by 2050, around half of the fossil fuel related $\mathrm{CO}_{2}$ emissions.

As a result of these changes total $\mathrm{CO}_{2}$ emissions of the energy sector decrease from around $500 \mathrm{Mt}$ $\mathrm{CO}_{2}$ in 2015 to less than $100 \mathrm{Mt} \mathrm{CO}_{2}$ in 2050.

\subsection{The effects of myopic foresight (MY-10 and MY-20 Scenarios)}

The usage of the myopic model in conjunction with the perfect foresight model shows the possible differences that one may encounter when planning on a short-term rather than a long-term basis. In fact, when comparing the results from the perfect foresight and the myopic model, one can notice structurally different decarbonisation pathways over the entire modelling period. The PF scenario presents long-term structural investments from the first model years. The myopic scenarios, on the other hand, delay investments in key low-carbon technologies, and reduce emissions with a short-term view - in which focus is given on the achievement of the short-term decarbonisation goals.

In the UK transport sector, for instance, planning in perfect-foresight results in early-stages investments on low-carbon transportation infrastructure. In detail, the model invests in electricity- and hydrogen- based transportation already in the near present, in order to then benefit from the hydrogenand electricity- transportation infrastructure in the last model years. On the other hand, myopic planning results in the UK's energy system reacting only to the near-term carbon mitigation requirements. Therefore it does not invest at early stages on the needed infrastructure for hydrogen and electric transportation. Therefore, the myopic model mitigates emissions mainly through the usage of hybrid and natural gas vehicles. That is because, with a late action, electric and hydrogen vehicles cannot be adopted fast enough in the system. This is both due to the need of an expanding infrastructure to support those vehicles, and to the diffusion limits of those vehicles.

As a result approximately $20 \mathrm{Mt}$ of $\mathrm{CO} 2 \mathrm{eq}$ more a year are emitted in the transport sector in the MY20 compared to the PF scenarios. Increasing myopia of the system make these dynamics stronger, with the transport sector decarbonising less with increasing myopia. In Figure 4 the difference in transport final energy demand between the MY-20 and the PF scenario is reported. 


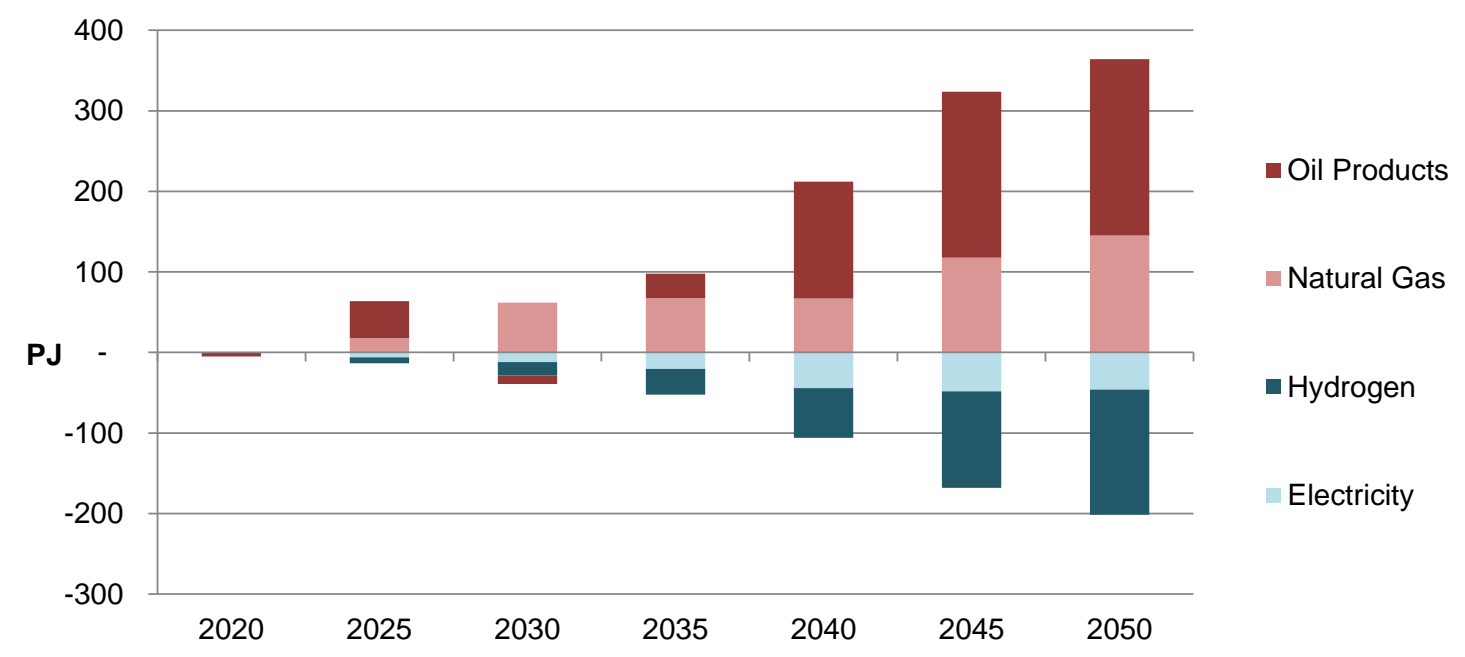

In the myopic scenarios, those extra emissions in transport are mostly offset through decreased emissions in the residential and services sectors. In fact, the stronger the myopia of the system the more those sectors are decarbonised in the last model years. That is because some residential sector technologies, such as heat pumps, which are already used in the UK and have a lower need of infrastructures, can be adopted faster than some low-carbon transportation technologies ${ }^{6}$. As a result, decarbonisation in the UK's residential and services sectors in the myopic model happens mostly with increased usage of low-carbon electric heating. In fact, electricity production decarbonises more the stronger the myopia of the system (Table 1).

Table 1 CO2 intensity of electricity by scenario, major power producers ( $\mathrm{gCO} / \mathrm{kWh})-2050$

\begin{tabular}{|l|c|c|c|}
\hline & PF & MY-20 & MY-10 \\
\hline CO2 intensity of electricity (gCO2/kWh) & 114 & 36 & 9 \\
\hline
\end{tabular}

For instance, by 2050 the MY10 scenario uses considerably more low-carbon electricity, provided mostly by renewable sources (Wind, Solar, Biomass and Geothermal) and natural gas generation with CCS (Figure 5). By 2050 the MY-10 scenario has over $80 \mathrm{GW}$ more of installed capacity of renewables-based electricity production, combined with around 20 PJ more of battery storage, compared to the PF scenario.

\footnotetext{
${ }^{6}$ see e.g. [33] and [37] for a further discussion on what affects technology adoption speed
} 


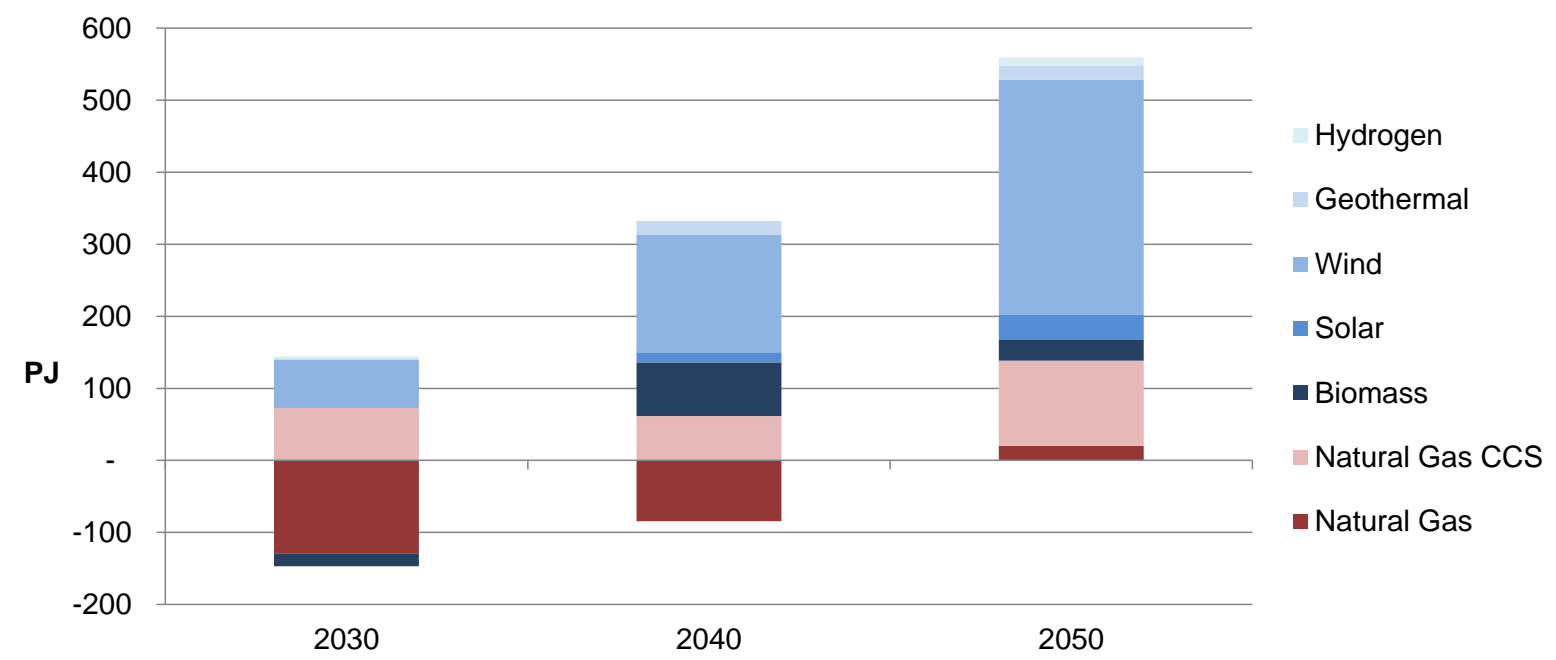

In fact, the electricity sector can decarbonise relatively fast in the myopic model, given the large amount of mature low-carbon electricity technologies which can be adopted in the UK. The fast and deep decarbonisation of the electricity sector has costs implications, as discussed in the next paragraphs.

Low-carbon electricity production plays a key role also in the decarbonisation of the industrial sector, where electricity usage is around $100 \mathrm{PJ}$ higher in the MY10 compared to the PF scenario, mostly due to a higher adoption of industrial heat pumps for low- and medium-temperature applications.

The key consequence of these different investment pathways is considerably higher costs in the myopic planning environment compared to the perfect foresight one (Figure 6). Myopic planning results in reduced investments in the first model years, as the investments needed to decarbonise the energy system are delayed. However, the cumulative costs to 2050 are considerably higher. These dynamics are more visible with increasing myopia. In fact, the MY-20 and MY-10 scenarios have over 100 and 500 billion pounds respectively of extra cumulative costs to achieve the decarbonisation goals in the 2015-2050 period. 


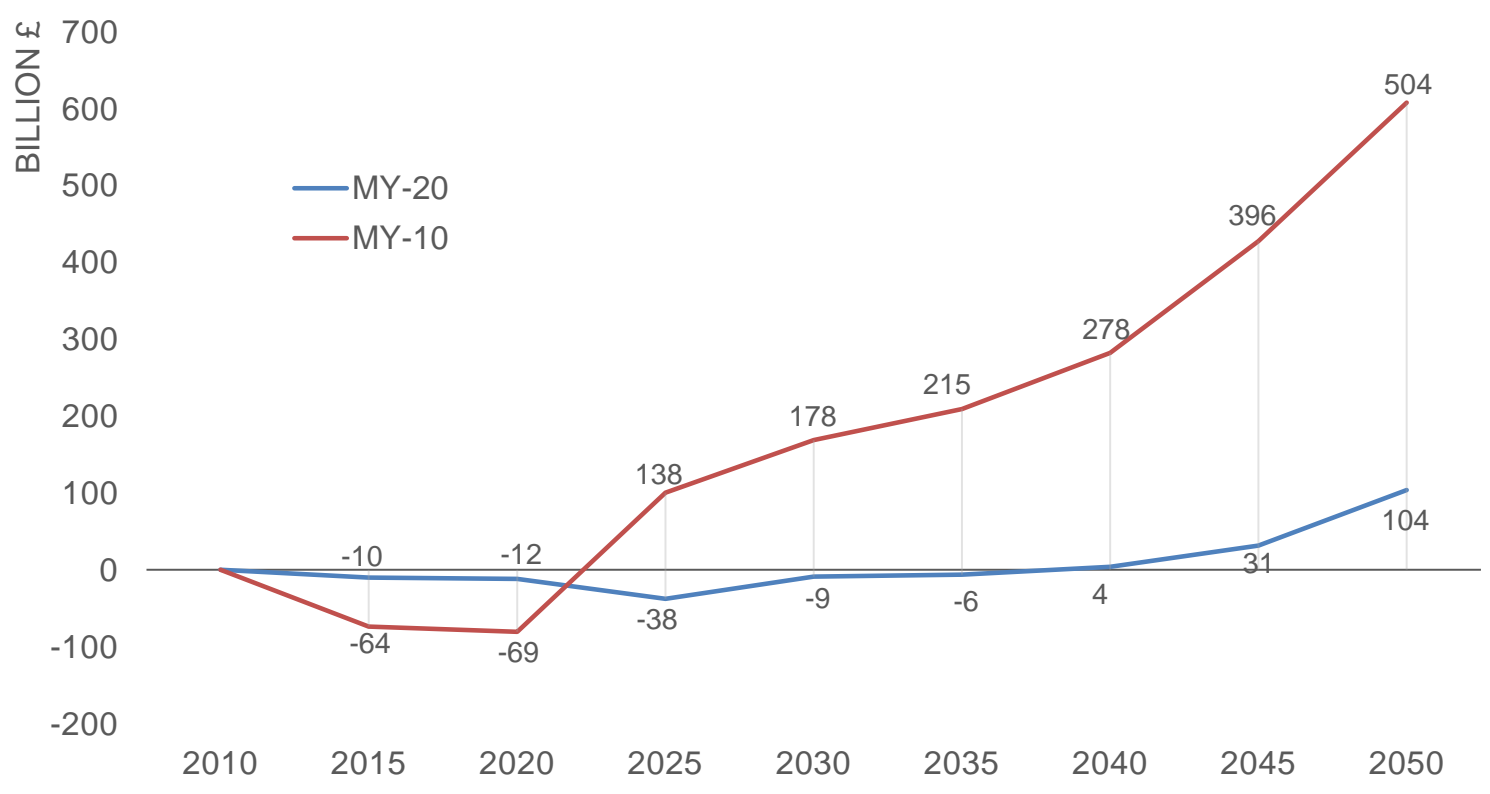

Most of the increase in cost is due to the fact that increased myopia results in more expensive technology choices at the system level. That is due to the fact that the cheapest technologies at the system level cannot be adopted fast enough to reach the same deployment as in the PF scenario, resulting in the need of adoption of more expensive solutions to decarbonise the energy system ${ }^{7}$. Those extra investments are mostly on the supply side, as investments on energy efficiency are comparable between the myopic and perfect foresight runs.

\subsection{The effect of a carbon tax obtained from a perfect foresight model in a myopic decisions environment (MY-10-CT and MY-20-CT scenarios)}

This section investigates how carbon prices obtained from a long-term perfect foresight model might perform in a myopic investment environment. For these scenarios, the emission prices obtained from the PF run are reported in Table 2:

Table 2 Carbon costs obtained from the PF-UKTM model run

\begin{tabular}{|l|l|l|l|l|}
\hline & 2020 & 2030 & 2040 & 2050 \\
\hline CO $_{2 e q}$ price [f/t CO2] & 37 & 99 & 128 & 288 \\
\hline
\end{tabular}

The carbon price, when used in the myopic model, results in the under-achievement of the UK's climate goals. In fact, emissions in 2050 for the MY-10-CT and MY-20-CT scenarios are 70 and 93 Mt CO2eq. higher per year than the perfect foresight run. Thus the MY-20-CT run achieves a

\footnotetext{
${ }^{7}$ A discussion on the effects of the assumed diffusion constraints is reported in section 3.4.
} 
reduction of approximately $70 \%$ and the MY-10-CT run of $67 \%$ of the GHG emissions in 2050 compared to the 1990 levels (Figure 7).

Figure 7 GHG emissions (MtCO2eq), PF versus MY-10-CT and MY-20-CT scenarios, 2010-2050

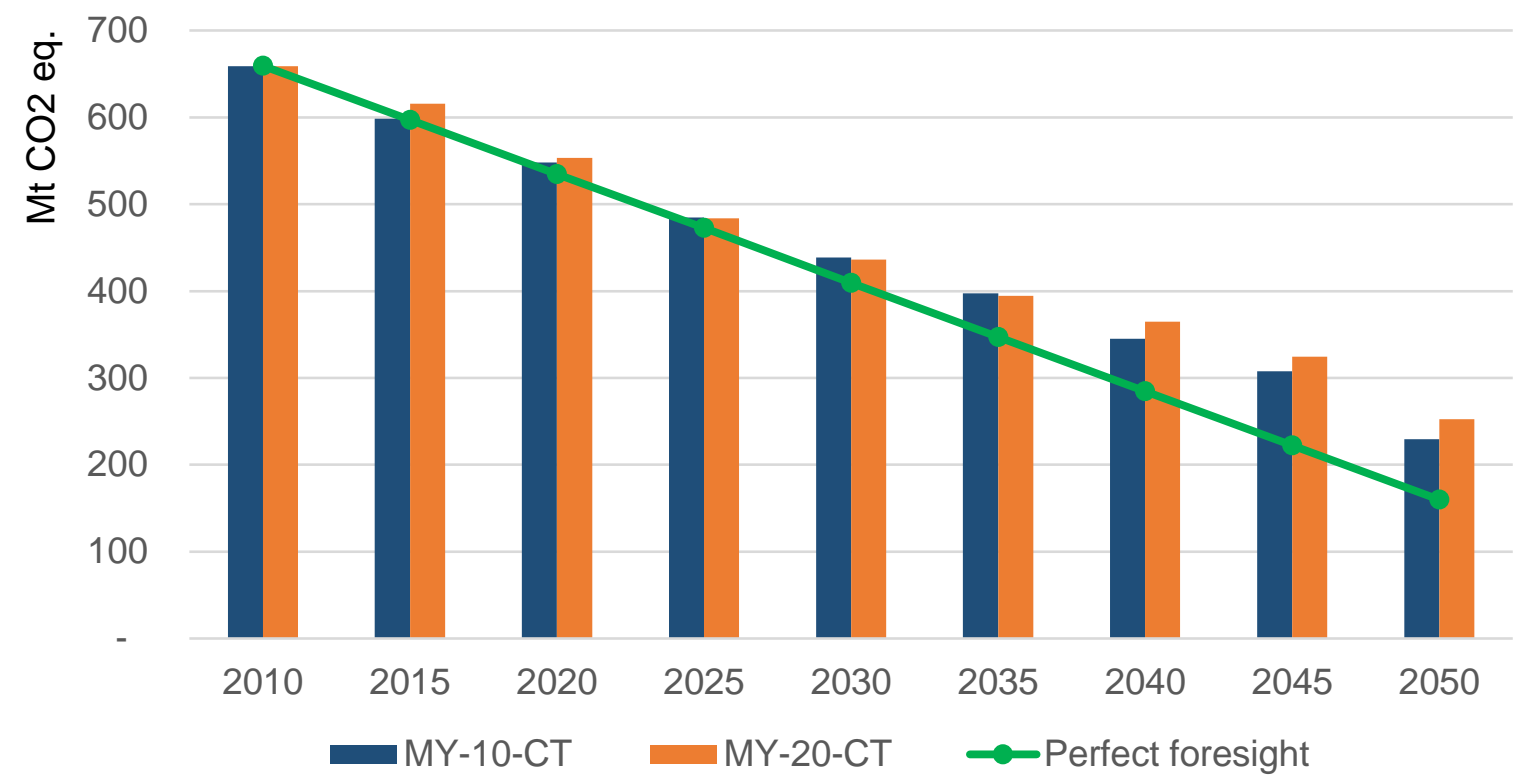

In fact, in the MY-10-CT and MY-20-CT scenarios, a range of technologies that were justified by the very high marginal prices of CO2 in the MY-10 and MY-20 scenarios are not adopted. This, in turn, indicates that a carbon tax obtained from a perfect foresight model might under-perform in a system where investments are made myopically. In fact, carbon prices would have to reach values over a thousand GBP/CO2eq in 2050 to achieve the $80 \%$ reduction in GHG emissions in the most myopic scenario considered in this study. This gives an indication on how 'last-mile' decarbonisation of the UK energy system (the last $5-15 \%$ decrease in emissions) might be extremely costly to implement, especially with increasing system myopia. Those high costs might, in turn, result in the nonachievement of the UK decarbonisation goals.

Such dynamics are interesting in two ways. First, they show that carbon prices might need to be adjusted depending on the assumed myopia of the UK's investment environment. Not considering the system myopia could result in over-optimistic assumptions, and in turn, in the non-achievement of the UK's climate targets. Second, it shows that last-mile decarbonisation can be extremely costly with marginal prices for each extra ton of abated $\mathrm{CO} 2 \mathrm{eq}$ reaching over a thousand pounds.

\subsection{Flexibility in the adoption of low-carbon technologies - a sensitivity analysis}

The achievable speed of adoption of low-carbon technologies can attenuate or amplify the effects of myopia in achieving UK's decarbonisation goals. An energy system which is able to transition fast to new low-carbon technologies is likely to be less affected by myopia. On the other hand, an energy 
system in which the transition is slow might result in extra costs and possibly difficulties in achieving the decarbonisation targets.

Assumptions for the diffusion constraints for low-carbon technologies in the UK TIMES model were selected after a rigorous review process of different stakeholders, including UCL, BEIS and several other partners [7]. In this context, technology diffusion constraints have been extensively investigated in literature. Diffusion of technologies may be limited by several institutional, behavioural and social factors [30] and there is no generally accepted theory that explains diffusion rate heterogeneity across technologies, regions or periods of time [31]. Several studies compared diffusion constrains used in optimisation models to historical trends, with no consensus. Certain studies found technology diffusion constraints in long-term energy optimisation models for selected technologies to be overoptimistic compared to historical trends (e.g. [32]) while others found diffusion constraints to be conservative compared to historical trends (e.g. [33]). These diverging results in literature make the value of a sensitivity analysis on the diffusion of technologies clear.

Therefore, to look at the interplay between energy system flexibility and myopia, selected model runs were made to evaluate the effect of a faster or slower diffusion of low-carbon energy technologies. For each of the PF, MY-20 and MY-10 scenarios an additional two model runs were made, one in which the maximum speed of adoption (in terms of the maximum annual growth rate) of low-carbon technologies was doubled ('fast' scenarios), and one in which it was halved ('slow' scenarios) ${ }^{8}$. In Figure 8 the results of this sensitivity analysis are reported, and presented in terms of cumulative cost difference in the 2010-2050 period between the considered model runs and the PF scenario.

\footnotetext{
${ }^{8}$ For the sensitivity analysis, diffusion constraints were all tightened (for the 'slow' scenarios) or all relaxed (for the 'fast' scenario) for the following constraints:

- In the electricity sector: all renewable-based electricity generation technologies and CCS

- In the service and residential sectors: a range of heating technologies (such as heat pumps, district heating, night heat storage, micro-CHP and solar- and biomass- based heating) and all conservation technologies.

- In the processes sector: a range of technologies for producing hydrogen, alcohol, bio-diesel, biogas, and bio oil.

- In the transport sector: all new hydrogen, electric and hybrid vehicles, both for the transport of people and of goods.

- In the industrial sector: over a 100 efficient and/or low carbon technologies in different industrial processes
} 
Figure 8 Cost difference between the PF scenario and the scenarios with diminished flexibility (PF 'slow', MY-20 'slow', MY-10 'slow') the reference scenarios (MY 10 and MY-20), and the increased flexibility scenarios (PF 'fast', MY-20 'fast', MY-10 'fast'). Billion GBP

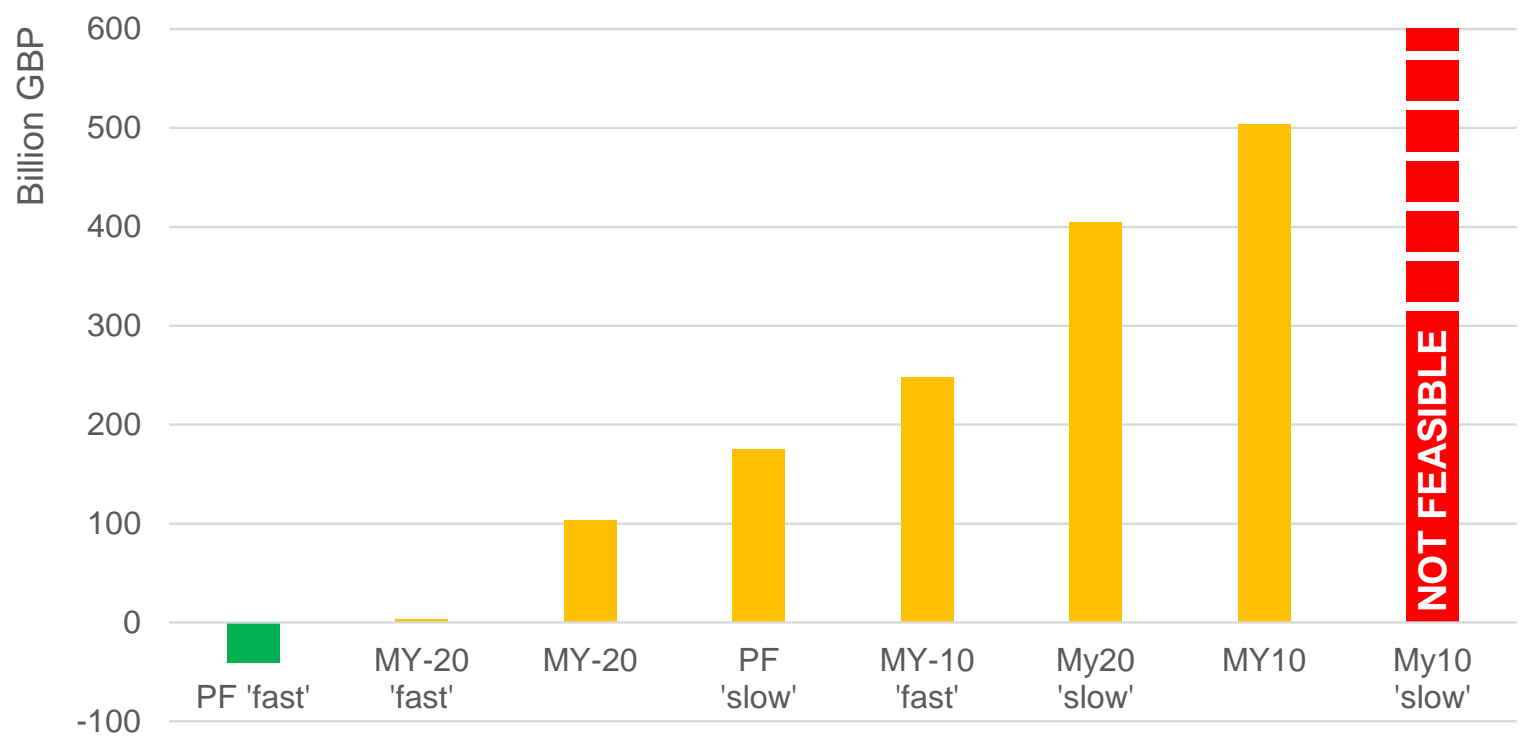

Regarding technology choice differences between the myopic and perfect foresight scenarios, the dynamics with more or less system flexibility are similar to the ones reported in section 3.2, but with different magnitude. As expected, increased system flexibility reduces the impacts of myopia and, conversely, lower flexibility affects myopic runs more than the perfect foresight one. In the case in which low-carbon technologies can be adopted twice as fast as in the UKTM base assumptions the scenario with a 20 year foresight have similar costs to the PF run. With fast technology adoption the scenario with a 10 year foresight (MY-10 'fast') is 250 billion GBP more expensive than the PF run, half of the cost difference with the MY-10 scenario.

The effects of a diminished system flexibility combined with myopia are considerable. The MY-20 'slow' scenario result in increased costs by approximately 400 billion GBP in the period 2010-2050, four times as much as the MY-20 scenario. The cost increase due to reduced flexibility is around 300 billion GBP, almost twice the increase observed for the PF scenario. More interestingly, the scenario with 10 years planning horizon and reduced system flexibility (MY-10 'slow') cannot achieve the goal of an $80 \%$ reduction in emissions. The maximum emission reduction that it can achieve is approximately $70 \%$. Moreover, achieving that $70 \%$ reduction in emissions in the scenario with a 10 year planning horizon and low system flexibility is approximately 250 billion GBP costlier than achieving an $80 \%$ reduction in GHG emissions in the standard perfect foresight scenario.

\subsection{Myopia, perfect foresight and decision making in the real world}


Our results suggest that myopia can lead to delayed low carbon investments and to higher costs than what the perfect foresight runs suggest. Conversely, stronger policy instruments than suggested by the perfect foresight runs are likely to be required, in order to reach the targets that have been set.

There is, however, no perfect foresight in the real world and all the elements of the future are uncertain to varying extent. The strategies suggested by the perfect foresight runs can be sensitive to such uncertainties, as the decisions made today are strongly influenced by what is implied to be known with certainty about the future. Myopic runs, in turn, are more conservative, considering only the needs of today and investing in technologies that are economically viable right now, essentially implying that the future (beyond the decision horizon) is so uncertain that it should not affect the today's decisions at all. In other words, while myopic decisions may not prepare for the future, they also can't get it wrong by putting all the eggs in one uncertain basket.

Keeping this rationale in mind, an alternative conclusion can be reached based on Figure 6: Since the cumulative cost difference between PF and MY-20 is small in 2050 (and in fact turns positive only in 2040), an adaptive, myopic planning strategy may provide a better result than the perfect foresight one (or "betting on a horse" strategy, in real world terms), in case major uncertainties are expected to exist for e.g. future policy goals, technology and resource availability or the development of energy service demands. On the other hand, changing assumptions about myopia (MY-10) or about speed of adoption (MY-10 Slow, MY-20 Slow) increases the cost difference between the long term (perfect foresight) planning and reactive strategies greatly, in some cases so much that the targets remain beyond reach.

The above further highlights the tension between keeping the needs of future decades in mind, while trying to avoid strategies that may strongly rely on uncertain developments. While highlighting the problems of not doing the former, our results can't provide generalised information about how the trade-off between these two should be made. This will always be a function of the nature and magnitude of the future uncertainties (among other things), which themselves are generally very difficult to quantify (making e.g. stochastic optimisation is also problematic, next to the other issues related to the methodology (e.g. computational requirements)). Our analysis does, however, provide information about the conditions under which long term planning is, in our modelling framework, a necessity and gives tools for the policy makers to analyse what the impacts of not making specific long term "bets" might be.

\section{Conclusions}

This paper shows that increasing myopia in energy system investments could result in the postponement (or cancellation) of strategic investments on key technologies, such as low-carbon transportation infrastructure. That, in turn, results in considerably increased costs to reach the 
decarbonisation goals. For instance, with investment decisions made every 10 years, the costs of achieving UK's carbon targets could increase by over 500 Billion pounds.

On the other hand, carbon prices estimated from perfect foresight optimisation models might be under-estimated. With increasing myopia of the system, those carbon prices would result in the nonachievement of UK's climate goals. Conversely, in order to reach the set targets, significantly higher carbon prices are required under myopia.

Additionally, the interplay between system flexibility and myopia also plays an important role in the achievement of the decarbonisation targets. Reduced system flexibility (in terms of the possible speed of adoption of new low-carbon technologies) combined with myopic investments in an implementation phase can further escalate the costs or result in the non-achievement of UK's decarbonisation goals.

Finally, this paper shows that the usage in tandem of myopic and perfect foresight optimisation energy models in energy planning can provide several benefits. The perfect foresight model can be used to suggest possible least-cost pathways to achieve long-term decarbonisation goals. That is valuable for setting policy goals with a long-term view. However, even if tools that assume perfect foresight are valuable to support long-term planning, there is no perfect foresight in the real world and all the elements of the future are uncertain to varying extent. Therefore, the counterpart myopic optimisation model can provide information regarding how those goals might be achieved in an implementation phase, in which different actors decision horizons might be shorter than the 40-50 years used in perfect foresight models. The outcomes from the myopic model can in turn be used for adjusting policies to take into account actors myopic behaviours.

Furthermore, this paper discusses how real world uncertainties might influence long term planning, and the value of using in tandem perfect foresight and myopic tools to analyse what the impacts of not making specific long term strategies might be (section 3.5).

Future work should enrich the analysis with more scenarios to capture the effect of major uncertainties, and at analysing the system with different myopic windows for each sector. Also, the effect of differentiated discount rates by sectors could be evaluated. Finally, the results from this exercise could be contextualised in the broader sustainability debate by adding water, land, and employment considerations to the results. A way to do that would be to complement the optimisation model cost results with multi criteria decision analyses (MCDA) (e.g. [34,35]).

\section{Acknowledgments}

This research was funded by the wholeSEM (EP/K039326/1) UK Research Council grant. 


\section{References}

[1] Parliament of the United Kingdom, Climate Change Act 2008, HM Gov. (2008) 1-103. doi:10.1136/bmj.39469.569815.47.

[2] CCC, The Fifth Carbon Budget: The next step towards a low-carbon economy, (2015).

[3] R. Kannan, N. Strachan, S. Pie, G. Anandarajah, N. Balta-Ozkan, UK MARKAL Model Documentation, (2007). https://www.ucl.ac.uk/energy-models/models/uk-markal/uk-markaldocumentation (accessed April 6, 2016).

[4] Department of Energy and Climate Change, The Carbon Plan: Delivering our low carbon future, Energy. (2011) 218. http://www.decc.gov.uk/assets/decc/11/tackling-climatechange/carbon-plan/3702-the-carbon-plan-delivering-our-low-carbon-future.pdf.

[5] Department of Trade and Industry, Energy white paper: meeting the energy challenge, London. (2007).

https://www.gov.uk/government/uploads/system/uploads/attachment_data/file/243268/7124.pd f (accessed April 7, 2016).

[6] UCL Energy Institute, UKTM-UCL, (2016). https://www.ucl.ac.uk/energymodels/models/uktm-ucl.

[7] Department of Energy \& Climate Change, Title: Impact Assessment for the level of the fifth carbon budget Impact Assessment (IA), (2016). http://www.legislation.gov.uk/ukia/2016/152/pdfs/ukia_20160152_en.pdf (accessed August 10, 2016).

[8] ETSAP, ETSAP partners and Times tool users, (2016). http://www.ieaetsap.org/web/Partner.asp\#Others (accessed April 6, 2016).

[9] IIASA, MESSAGE model, (2016). http://www.iiasa.ac.at/web/home/research/modelsData/MESSAGE/MESSAGE.en.html (accessed April 6, 2016).

[10] M. Howells, H. Rogner, N. Strachan, C. Heaps, H. Huntington, S. Kypreos, A. Hughes, S. Silveira, J. DeCarolis, M. Bazillian, A. Roehrl, OSeMOSYS: The Open Source Energy Modeling System. An introduction to its ethos, structure and development., Energy Policy. 39 (2011) 5850-5870. doi:10.1016/j.enpol.2011.06.033.

[11] F. Fuso Nerini, R. Dargaville, M. Howells, M. Bazilian, Estimating the cost of energy access: The case of the village of Suro Craic in Timor Leste, Energy. 79 (2015) 385-397. doi:10.1016/j.energy.2014.11.025. 
[12] I. Keppo, M. Strubegger, Short term decisions for long term problems - The effect of foresight on model based energy systems analysis, Energy. 35 (2010) 2033-2042.

doi:10.1016/j.energy.2010.01.019.

[13] G.J. Kramer, M. Haigh, No quick switch to low-carbon energy., Nature. 462 (2009) 568-9. doi:10.1038/462568a.

[14] J. Markard, R. Raven, B. Truffer, Sustainability transitions: An emerging field of research and its prospects, Res. Policy. 41 (2012) 955-967. doi:10.1016/j.respol.2012.02.013.

[15] R. Loulou, G. Goldstein, A. Kanudia, A. Lettila, U. Remme, E. Wright, G. Giannakidis, K. Noble, Documentation for the TIMES Model, (2016). http://www.ieaetsap.org/web/Documentation.asp (accessed April 3, 2017).

[16] S. Babrowski, T. Heffels, P. Jochem, W. Fichtner, Reducing computing time of energy system models by a myopic approach: A case study based on the PERSEUS-NET model, Energy Syst. 5 (2014) 65-83. doi:10.1007/s12667-013-0085-1.

[17] B.C. O'Neill, K. Riahi, I. Keppo, Mitigation implications of midcentury targets that preserve long-term climate policy options., Proc. Natl. Acad. Sci. U. S. A. 107 (2010) 1011-1016. doi:10.1073/pnas.0903797106.

[18] B. Nykvist, Limited foresight in a linear cost minimisation model of the global energy system, CHALMERS Univ. Technol. (2005) 53.

[19] F. Hedenus, C. Azar, K. Lindgren, Induced Technological Change in a Limited Foresight Optimization Model Author ( s ): Fredrik Hedenus , Christian Azar and Kristian Lindgren Source: The Energy Journal, Vol .27, Special Issue : Endogenous Technological Change and the Economics of Atmos, Energy J. 27 (2015) 109-122.

[20] A. s. Kydes, Energy Policy Modeling: United States and Canadian Experiences. Chapter 7:THE BROOKHAVEN ENERGY SYSTEM OPTIMIZATION MODEL: ITS VARIANTS AND USES, in: 1980. http://link.springer.com/10.1007/978-94-009-8748-7.

[21] US Department of Energy, Model Documentation Report: System for the Analysis of Global Energy Markets Volume 1 Model Documentation Table of contents, 2003.

[22] D. Martinsen, A Time Step Energy Process Model for Germany - Model Structure and Results A Time Step Energy Process Model for Germany - Model Structure and, Energy Stud. Rev. 14 (2006) 35-57.

[23] F.G.N. Li, Actors behaving badly: Exploring the modelling of non-optimal behaviour in energy transitions, Energy Strateg. Rev. 15 (2017) 57-71. doi:10.1016/j.esr.2017.01.002. 
[24] H.E. Daly, B. Fais, UK TIMES MODEL OVERVIEW, (2014). https://www.ucl.ac.uk/energymodels/models/uktm-ucl/uktm-documentation-overview (accessed April 4, 2017).

[25] H.E. Daly, K. Scott, N. Strachan, J. Barrett, Indirect CO2 Emission Implications of Energy System Pathways: Linking IO and TIMES Models for the UK., Environ. Sci. Technol. 49 (2015) 10701-9. doi:10.1021/acs.est.5b01020.

[26] B. Fais, N. Sabio, N. Strachan, The critical role of the industrial sector in reaching long-term emission reduction, energy efficiency and renewable targets, Appl. Energy. 162 (2016) 699712. doi:10.1016/j.apenergy.2015.10.112.

[27] B. Fais, I. Keppo, M. Zeyringer, W. Usher, H. Daly, Impact of technology uncertainty on future low-carbon pathways in the UK, Energy Strateg. Rev. 13-14 (2016) 154-168. doi:10.1016/j.esr.2016.09.005.

[28] S. Pye, F.G.N. Li, J. Price, B. Fais, Achieving net-zero emissions through the reframing of UK national targets in the post-Paris Agreement era, Nat. Energy. 2 (2017) 17024. doi:10.1038/nenergy.2017.24.

[29] A. Lehtilä, User Control Switches in TIMES, (2013) 1-21.

[30] G. Iyer, N. Hultman, J. Eom, H. McJeon, P. Patel, L. Clarke, Diffusion of low-carbon technologies and the feasibility of long-term climate targets, Technol. Forecast. Soc. Change. 90 (2015) 103-118. doi:10.1016/j.techfore.2013.08.025.

[31] B.D. Leibowicz, V. Krey, A. Grubler, Representing spatial technology diffusion in an energy system optimization model, Technol. Forecast. Soc. Change. 103 (2015) 1-14. doi:10.1016/j.techfore.2015.06.001.

[32] W. McDowall, Are scenarios of hydrogen vehicle adoption optimistic? A comparison with historical analogies, Environ. Innov. Soc. Transitions. (2015). doi:10.1016/j.eist.2015.10.004.

[33] C. Wilson, A. Grubler, N. Bauer, V. Krey, K. Riahi, Future capacity growth of energy technologies: Are scenarios consistent with historical evidence?, Clim. Change. 118 (2013) 381-395. doi:10.1007/s10584-012-0618-y.

[34] S.E. Shmelev, J.C.J.M. Van Den Bergh, Optimal diversity of renewable energy alternatives under multiple criteria: An application to the UK, Renew. Sustain. Energy Rev. 60 (2016) 679-691. doi:10.1016/j.rser.2016.01.100.

[35] F. Fuso Nerini, M. Howells, M. Bazilian, M.F. Gomez, Rural electrification options in the Brazilian Amazon. A multi-criteria analysis, Energy Sustain. Dev. 20 (2014) 36-48. doi:10.1016/j.esd.2014.02.005. 
[36] L.M.H. Hall, A.R. Buckley, A review of energy systems models in the UK: Prevalent usage and categorisation, Appl. Energy. 169 (2016) 607-628. doi:10.1016/j.apenergy.2016.02.044.

[37] A. Grubler, C. Wilson, G. Nemet, Apples, oranges, and consistent comparisons of the temporal dynamics of energy transitions, Energy Res. Soc. Sci. 22 (2016) 18-25. doi:10.1016/j.erss.2016.08.015. 